\title{
Aplicação do "ISAREG" no manejo da irrigação na cultura da melancia no Baixo Acaraú, Ceará ${ }^{1}$
}

\author{
Using "ISAREG" on irrigation management in watermelon cultivation in the Baixo \\ Acaraú, Ceará
}

\author{
Kleiton Rocha Saraiva ${ }^{2 *}$, Francisco Marcus Lima Bezerra ${ }^{3}$, Francisco de Souza $^{3}$ e Luis de França Camboim \\ Neto $^{3}$
}

\begin{abstract}
RESUMO - O objetivo do presente trabalho foi aplicar o modelo "ISAREG" no manejo da irrigação da cultura da melancia, no Perímetro Irrigado Baixo Acaraú (PIBA). Para tanto, analisou-se o balanço hídrico do solo, elaborando um calendário de irrigação, visando à máxima produtividade da cultura, para as condições edafoclimáticas do PIBA, para uma data de plantio, comparando-o com o manejo de irrigação atualmente adotado pelos irrigantes. Visando a aplicação prática do ISAREG, o modelo foi alimentado com dados mensais de variáveis climatológicas, dados de precipitação, de solo, e informações da cultura. Finalmente, selecionou-se uma opção de manejo da irrigação disponível no ISAREG, e o mesmo realizou a simulação do balanço hídrico do solo. Para se tomar conhecimento acerca do manejo da irrigação, realizado pelo irrigante do PIBA foram aplicados questionários. A pesquisa evidenciou que os irrigantes do PIBA, no cultivo da melancia não estão manejando adequadamente os recursos hídricos. Durante o ciclo da cultura, o irrigante está aplicando, em excesso, cerca de 215,2 mm de água, em alguns períodos, e está proporcionando um déficit hídrico de 24,2 $\mathrm{mm}$ à cultura, em outros períodos.
\end{abstract}

Palavras-chave: Água. Balanço hídrico. Software.

\begin{abstract}
The objective of this study was to apply the ISAREG software model to the irrigation management of watermelon in the Lower Acaraú Irrigated Perimeter (LAIP). To this end, the soil water-balance was analysed, developing an irrigation schedule which aimed for maximum crop yield for the soil and climatic conditions of the LAIP for a specific planting date and comparing it to the irrigation scheme currently adopted by irrigators. With an aim to the practical application of ISAREG, the model was supplied monthly with climatic variables, precipitation and soil data, and information on the crop. Finally, an irrigation option available in ISAREG was selected, and a simulation of the soil water-balance was carried out. Questionnaires were used in order to get information about the irrigation scheme employed at the LAIP. The research showed that the producers of watermelon at the LAIP are not properly managing water resources. During the crop cycle, irrigators are applying an excess of about $215.2 \mathrm{~mm}$ of water at some periods, and a deficit of $24.2 \mathrm{~mm}$ to the crops in others.
\end{abstract}

Key words: Water. Water balance. Software.

\footnotetext{
*Autor para correspondência

${ }^{1}$ Recebido para correspondência em 09/09/2011; aprovado em 16/06/2012

Parte da Dissertação de Mestrado do primeiro autor; Pesquisa financiada pelo CNPq através da Universidade Federal do Ceará-UFC

${ }^{2}$ Programa de Pós-Graduação em Engenharia Agrícola/PPGEA, Centro de Ciência Agrárias/UFC, Av. Mister Hull s/n, Campus do Pici, Bloco 804, Fortaleza-CE, Brasil, 60.455-760, kleitonagro@bol.com.br

${ }^{3}$ Departamento de Engenharia Agrícola, Centro de Ciência Agrárias/UFC, Av. Mister Hull s/n, Campus do Pici, Bloco 804, Fortaleza-CE, Brasil, 60.455-760,mbezerra@ufc.br, fsouza@ufc.br, camboim@ufc.br
} 


\section{INTRODUÇÃO}

A agricultura irrigada utiliza entre 70 e $80 \%$ da água doce disponível no mundo. Segundo Annan (2005) a produção global de alimentos terá que aumentar em $60 \%$, durante o período de 2000 a 2030, para satisfazer a crescente demanda populacional. Isso acarretará num aumento de $14 \%$ na demanda de água para a agricultura irrigada.

As políticas públicas, referentes à água, foram iniciadas no Estado do Ceará, em 1919, com a construção de açudes, realizada pelo IFOCS (Inspetoria Federal de Obras Contra as Secas), precursora do atual Departamento Nacional de Obras Contra as Secas (DNOCS), que no início da década de 60 começou a construção dos perímetros públicos de irrigação.

O Estado do Ceará conta, hoje, com o perímetro irrigado mais moderno do País, que é o Baixo Acaraú PIBA. Neste, assim como nos demais perímetros irrigados do Nordeste brasileiro, o irrigante não sabe, quanto nem quando irrigar.

Segundo Santana et al. (2008) dentre os perímetros irrigados, localizados no Ceará, o Baixo Acaraú é o segundo maior, em termos de demanda hídrica $\left(151,92 \mathrm{hm}^{3} \mathrm{ano}^{-1}\right)$ ficando atrás apenas do perímetro irrigado Tabuleiro de Russas $\left(188,28 \mathrm{hm}^{3} \mathrm{ano}^{-1}\right)$.

Atualmente, cerca de 2.053 ha estão sendo irrigados no PIBA. A quantidade média de água aplicada à cultura da melancia é de, aproximadamente $117 \mathrm{~m}^{3} \mathrm{ha}^{-1} \mathrm{~d}^{-1}$. Considerando um ciclo médio da melancia no PIBA de 70 dias, significa dizer que os irrigantes estão aplicando cerca de $8.173 \mathrm{~m}^{3}$ de água por hectare em todo o ciclo da cultura. Ainda, levandose em consideração que o espaçamento adotado pelos irrigantes, para a cultura é de 3 × $1 \mathrm{~m}$, os mesmos estão aplicando, diariamente, cerca de 35 litros de água por planta.

O manejo racional da irrigação objetiva maximizar a eficiência do uso da água e minimizar o consumo de energia, mantendo favoráveis as condições de umidade do solo e de fitossanidade das plantas, levando em consideração as condições climáticas do local de cultivo, bem como as características da cultura (PEREIRA, 2004). Uma técnica efetiva e de baixo custo, para reduzir problemas de manejo da irrigação é a adoção de calendários de irrigação, através da utilização de "softwares" computacionais.

Um modelo que tem se destacado no âmbito internacional é o ISAREG, que é um software de simulação do balanço hídrico no solo que é capaz de lidar com a ascensão capilar e com percolação através da zona radicular (PEREIRA, 2004; PETILLO; CASTEL, 2008). O ISAREG tem sido utilizado em vários países e aplicações recentes foram realizadas, porém o mesmo não foi aplicado para as condições da agricultura irrigada do Estado do Ceará, razão pela qual decidiu-se por realizar esta pesquisa.

Segundo Andrade Júnior et al. (2006), o cultivo da melancieira é uma atividade de alto risco devido à sazonalidade nos preços recebidos pelos produtores, e aos problemas agronômicos da cultura, como a baixa produtividade, que está relacionada ao manejo inadequado da irrigação e da adubação.

Por outro lado, segundo Figueirêdo et al. (2009) a melancia tem-se destacado como uma das principais espécies olerícolas cultivadas no País. Ademais, a melancia (Citrullus lanatus, Schrad) é uma das culturas de ciclo curto, mais cultivadas nos perímetros irrigados, administrados pelo DNOCS. Assim como para a quase totalidade das culturas, um dos fatores mais importantes no cultivo da melancia é o manejo de irrigação.

A estimativa acurada da evapotranspiração da cultura é importante para determinar a demanda de água e para planejar a sua irrigação em escala regional (KASHYAP; PANDA, 2001).

Portanto, objetivou-se calcular as necessidades hídricas da cultura da melancia, utilizando o ISAREG, pela analise do balanço hídrico do solo, elaborando um calendário de irrigação, visando a máxima produtividade da cultura da melancia, para as condições edafoclimáticas do Perímetro Irrigado Baixo Acaraú (PIBA), para 1 (uma) data de plantio, comparando-o com o manejo de irrigação atualmente adotado pelos irrigantes do PIBA.

\section{MATERIAL E MÉTODOS}

Visando a aplicação prática do ISAREG foram coletadas informações acerca do PIBA, bem como da cultura da melancia. Dentre as principais informações que foram coletadas, algumas sobre o manejo da irrigação (quanto e quando irrigar), adotado pelos irrigantes do PIBA, o turno de irrigação para a melancia, as características físicas do solo representativo do perímetro, todos os coeficientes técnicos (oriundos de pesquisas locais), referentes à cultura da melancia, bem como a obtenção de série histórica de dados climatológicos do PIBA.

O Perímetro Irrigado Baixo Acaraú está localizado na região norte do Estado do Ceará no trecho final da bacia do rio Acaraú, abrangendo áreas dos municípios de Acaraú, Bela Cruz e Marco. Geograficamente é definida pelas coordenadas $40^{\circ} 08^{\prime}$ de longitude Oeste, $02^{\circ} 53^{\prime}$ latitude Sul e $16,5 \mathrm{~m}$ de altitude (SISTEMA DE INFORMAÇÕES DOS RECURSOS HÍDRICOS DO CEARÁ, 2002). 
O Baixo Acaraú tem uma área irrigável de 8.440 ha, mas, atualmente, estão sendo irrigados 2.053 ha.

De acordo com a classificação de Köppen, o clima da área é do tipo Aw', quente e úmido com chuvas de verão-outono, com precipitação anual média de $960 \mathrm{~mm}$ e evaporação de aproximadamente $1.600 \mathrm{~mm}$ anuais. Os solos são predominantemente classificados como Neossolo Flúvico, Argissolo e Neossolo Quartzarênico. No que se refere ao relevo, a região é caracterizada por uma topografia suave-ondulada, porém com uma forte declividade longitudinal (AQUINO et al., 2008).

Visando utilizar uma série histórica (1977 a 2007) representativa das variáveis climatológicas, para o cálculo da evapotranspiração de referência (ETo), utilizou-se as informações fornecidas pelo INMET (Instituto Nacional de Meteorologia), pois para realizar o cálculo da ETo, o ISAREG, através da equação de Penman-Monteith/FAO, descrita por Allen et al. (1994), requereu as seguintes informações climáticas: (a) temperatura máxima, Tmáx; (b) temperatura mínima, Tmin; (c) umidade relativa do ar, UR; (d) velocidade do vento, Vv; e, (e) insolação, In. Também foram necessárias as seguintes informações adicionais: altitude e latitude do local.

Os bons resultados do método PM/FAO foram atestados por Lopéz-Urrea et al. (2006) que ao testarem equações de estimativa de ETo em um clima semiárido, concluíram que o método de PM/FAO foi o mais adequado para calcular a ETo média diária, quando comparado às medidas lisimétricas, embora tenha produzido subestimativas consideráveis.

Quanto aos dados de solo, as variáveis necessárias pelo ISAREG para a simulação foram a capacidade de campo, o ponto de murcha permanente, ambas em fração de volume, e as profundidades das camadas de amostragem do solo. Os dados de solo foram obtidos por Moreira (2009). Vale salientar que as informações físicas do solo, que foram utilizadas, são representativas de um Neossolo Quartzarênico, solo esse predominante na área atual de exploração agrícola do PIBA (Tabela 1).
A melancia "Citrullus vulgaris Schrad" é cultivada no Perímetro em um espaçamento de $3 \times 1 \mathrm{~m}$. A cultura tem um ciclo em torno de 70 dias. As durações das fases fenológicas da melancia são as seguintes, de acordo com o modelo ISAREG: a) 10 dias do plantio até a primeira irrigação; b) 10 dias de início de crescimento vegetativo; c) 17 dias de cobertura total e floração; d) 12 dias de formação de frutos; e) 7 dias de início da senescência das folhas; e, f) 14 dias de colheita e final do ciclo.

Em relação à profundidade efetiva do sistema radicular (z), por fase fenológica, utilizaram-se as seguintes profundidades, utilizadas por pesquisadores locais: a) $0,1 \mathrm{~m}$ do plantio até a primeira irrigação; b) 0,2 m de início de crescimento vegetativo; c) $0,3 \mathrm{~m}$ de cobertura total e floração; d) $0,35 \mathrm{~m}$ de formação de frutos; e) 0,4 m de início da senescência das folhas; e, f) $0,4 \mathrm{~m}$ de colheita e final do ciclo. Quanto ao fator de esgotamento máximo de água disponível (p) não foi possível obter, com precisão esse fator, principalmente, por fase fenológica. Portanto, adotou-se um valor de "p" médio utilizado por pesquisadores locais, para a cultura da melancia, de 0,2. Os coeficientes da cultura $(\mathrm{Kc})$ da melancia que foram utilizados são oriundos da pesquisa local, realizada por Miranda et al. (2004) que trabalhando com lisimetria de precisão, encontraram os seguintes Kc's da cultura da melancia: 0,39 no estádio inicial, 1,31 no estádio intermediário e 0,7 no estádio final. Quanto aos valores supracitados, optou-se por não se utilizar valores recomendados pela FAO (Food Agriculture Organization), devido ao fato de que tais manuais recomendam informações culturais, calculadas nas condições climáticas do mediterrâneo, sendo assim inadequadas no caso de culturas cultivadas em clima tropical.

Visando tomar conhecimento de como o irrigante realiza o manejo da irrigação no PIBA foram aplicados dois modelos de questionário técnico. O primeiro, que foi aplicado aos irrigantes, teve como principais objetivos, saber: quais as culturas mais exploradas, quando ocorre a irrigação, quanto de água é aplicado, por cultura, qual a concepção dos irrigantes em se tratando do uso da água. $\mathrm{O}$ segundo foi aplicado ao gerente do Distrito de irrigação.

Tabela 1 - Dados de solo representativos do PIBA, utilizados na simulação com o ISAREG

\begin{tabular}{lcccc}
\hline \multicolumn{1}{c}{ Camada do solo } & $1^{\circ}$ camada & $2^{\circ}$ camada & $3^{\circ}$ camada & $4^{\circ}$ camada \\
\hline Camada Superior $(\mathrm{m})$ & 0,00 & 0,08 & 0,23 & 0,38 \\
Camada Inferior $(\mathrm{m})$ & 0,08 & 0,23 & 0,38 & 0,53 \\
Espessura da Camada (m) & 0,08 & 0,15 & 0,15 & 0,15 \\
Capacidade de campo (FC) & 0,13 & 0,24 & 0,19 & 0,23 \\
Ponto de Murcha (WP) & 0,08 & 0,16 & 0,08 & 0,12 \\
\hline
\end{tabular}

Fonte: Moreira, 2009 
Este teve como principais objetivos, saber: dos gestores sobre suas opiniões e expectativas, quanto ao aumento de produção no PIBA, analisar qual a disponibilidade dos irrigantes em pagar as tarifas de uso da água, qual a função do Distrito de irrigação na busca pela economia da água de irrigação.

Após a entrada de dados no modelo de simulação, o ISAREG gerou informações sobre os aspectos relacionados ao balanço hídrico do solo, bem como acerca do manejo da irrigação. As informações geradas foram as seguintes: lâmina de água aplicada durante todo o ciclo da cultura; lâmina de água percolada ao longo do ciclo da cultura; lâmina de água por ascensão capilar; necessidade de lixiviação (se houver); curva do coeficiente de cultivo (Kc); evapotranspiração da cultura (ETc), ao longo de todo o ciclo; e variação completa do armazenamento da água no solo.

Para o cálculo das necessidades hídricas da cultura (ETc) o ISAREG utilizou os valores de ETo (mensais), calculados pelo mesmo, utilizando dados climatológicos e os coeficientes culturais da melancia $(\mathrm{Kc})$. Porém, vale salientar que o ISAREG permite a entrada de dados diários de coeficientes cultural, o que refletiria em maior precisão na ETc, mas devido à escassez de dados, utilizou os Kc's: inicial, intermediário e final, oriundos de resultados de pesquisas locais (MIRANDA et al., 2004). Com isso, a ETc foi calculada através do produto entre a ETo e o coeficiente cultural $(\mathrm{Kc})$. Vale salientar que é de grande importância, se utilizar dados oriundos de pesquisas locais, pois Moreira et al. (2010) analisando médias de evapotranspiração horária, utilizando o modelo SEBAL, evidenciaram significativa variabilidade climática, em regiões do Estado do Ceará.

Após a seleção do tipo de manejo de irrigação (manejo ótimo de irrigação), o modelo foi alimentado acerca do total de água disponível no solo (TAW) no momento do início da irrigação, pois foi a partir do TAW indicado e simulado, de informações do fator de disponibilidade de água no solo (p), e da profundidade efetiva do sistema radicular (z), que o ISAREG calculou a capacidade de retenção de água no solo, a percolação profunda (q), durante o balanço hídrico, e a água prontamente disponível numa fração de solo (RAW), num certo momento do ciclo da cultura. Somando-se à ETc, foram inseridos dados de precipitação (também oriundos de série histórica), pois o modelo de simulação, a partir das informações de precipitação total, estima o que vai ser considerado como chuva efetiva, sendo informação necessária na geração do balanço hídrico no solo.

Após esse processo, o ISAREG determinou a variação de armazenamento da água no solo $(\Delta \mathrm{h})$, o fluxo de água no solo (q), a relação entre a evapotranspiração real e a máxima, percolação e/ou ascensão capilar, e eficiência teórica de irrigação, resultando no completo balanço hídrico do solo, gerando um calendário de irrigação, para a opção de manejo da irrigação pré-selecionado. Finalmente, informando ao usuário, para as condições de clima, solo e cultura fornecidos, quando e quanto se deve irrigar a cultura da melancia.

Em se tratando das opções do manejo da irrigação, no caso deste trabalho optou-se pelo cálculo da "lâmina para o máximo rendimento", onde o ISAREG considera que a lâmina de água no solo nunca é maior que "p", e a lâmina de irrigação deverá sempre deixar o solo à capacidade de campo.

Foi elaborado um calendário de irrigação, para a opção de manejo ótimo e um com entradas de datas e lâminas, a partir de dados oriundos da pesquisa "in loco", realizada junto aos irrigantes. Em relação às datas de plantio, foram elaborados calendários para a data de plantio de 01 de setembro, visando simular uma condição em que a região não se encontra no período das chuvas. Foi realizada uma análise comparativa entre a quantidade de água que os irrigantes estão aplicando à cultura da melancia no PIBA e a quantidade de água que o ISAREG recomendou, através de suas simulações (calendários de irrigação), com a utilização de dados históricos de ETo, com ETc's simuladas, pois as mesmas não foram medidas no campo.

\section{RESULTADOS E DISCUSSÃO}

As variáveis mais relevantes, geradas pelo ISAREG, no que tange às necessidades hídricas da cultura e ao calendário de irrigação, foram: a evapotranspiração de referência, a evapotranspiração da cultura, e o balanço hídrico do solo.

Após a entrada dos dados das variáveis climatológicas representativas do Baixo Acaraú no ISAREG, o modelo calculou a evapotranspiração de referência (ETo), fazendo uma média diária, de cada mês do ano (Tabela 2).

Ao se verificar a Tabela 2, torna-se possível observar que a ETo aumenta com o passar dos meses. No mês de setembro (início do ciclo) a ETo calculada pelo ISAREG foi de $6,17 \mathrm{~mm} \mathrm{dia}^{-1}$, e no mês de novembro (final do ciclo) a ETo foi de 6,14 $\mathrm{mm} \mathrm{dia}^{-1}$. Miranda et al. (2004) ao pesquisarem a ETo para as condições de Paraipaba-CE, verificaram valores de ETo igual a $3,83 \mathrm{~mm} \mathrm{dia}^{-1}$ (início do ciclo) e de 4,86 mm dia-1 (final do ciclo). Já Oliveira (1999) em pesquisa realizada no mesmo perímetro de irrigação, encontrou valores de ETo igual a 3,82 $\mathrm{mm} \mathrm{dia}^{-1}$ (início do ciclo) e de $4,83 \mathrm{~mm} \mathrm{dia}^{-1}$ (final do ciclo). 
Tabela 2 - Evapotranspiração de referência - ETo do Baixo Acaraú, calculada pelo ISAREG

\begin{tabular}{lcc}
\hline \multicolumn{1}{c}{ Mês } & $\begin{array}{c}\text { Evapotranspiração de Referência } \\
\left(\mathrm{mm} \mathrm{dia}^{-1}\right)\end{array}$ \\
\hline Janeiro & 3,74 \\
Fevereiro & 4,20 \\
Março & 3,71 \\
Abril & 3,54 \\
Maio & 3,85 \\
Junho & 4,19 \\
Julho & 4,97 \\
Agosto & 5,71 \\
Setembro & 6,17 \\
Outubro & 6,34 \\
Novembro & 6,14 \\
Dezembro & 5,67 \\
\hline
\end{tabular}

Sabe-se que de acordo com o comportamento das variáveis climátológicas (temperatura máxima, temperatura mínima, umidade relativa do ar, velocidade do vento, e insolação) a evapotranspiração de referência é afetada. Pois nos meses de maiores registros de temperatura, de velocidade do vento e de radiação solar e menores observações de umidade relativa do ar, verificou-se maior ETo.

Na Figura 1 é possível visualizar a curva de ETc estimada pelo ISAREG.
Os maiores valores verificados no período de 2 dias foram os presentes no mês de outubro (16,02 mm), o que representa uma ETc de 8,01 $\mathrm{mm} \mathrm{dia}^{-1}$. Bezerra e Oliveira (1999) verificaram ETc da melancia de $8,7 \mathrm{~mm} \mathrm{dia}^{-1}$, com 45 dias de ciclo da cultura. Já nos primeiros 30 dias do ciclo da cultura, a ETc média foi de $7,18 \mathrm{~mm} \mathrm{dia}^{-1}$. No final do ciclo da cultura, verificou-se, para o período de 2 dias, ETc média de 11,26 mm, o que resulta em uma ETc de 5,63 $\mathrm{mm} \mathrm{dia}^{-1}$. Miranda et al. (2004) encontraram, ETc média de 4,2 $\mathrm{mm} \mathrm{dia}^{-1}$, ao final do ciclo da cultura da melancia. A ETc total do ciclo foi de 409,1 mm. Oliveira (1999) verificou essa ETc de 267,1 mm, mas para uma época de plantio diferentes dos demais. Já considerando o que afirmara Santana et al. (2008), a demanda evapotranspirativa total do ciclo da cultura da melancia seria de cerca de $600 \mathrm{~mm}$, ou seja, superestimando seu requerimento real.

Quanto às variáveis climatológicas analisadas durante os meses do ano, o principal aspecto foi relacionado à evapotranspiração de referência (ETo), pois foi durante o ciclo da cultura (setembro, outubro e novembro), que foram observados os maiores valores de ETo, calculados pelo ISAREG, para as condições climáticas do Baixo Acaraú, sendo $6,17 \mathrm{~mm}, 6,34$ e $6,14 \mathrm{~mm}$, respectivamente.

Quanto aos aspectos referentes à cultura da melancia, o entendimento do coeficiente de cultivo (Kc) foi fundamental, pois observou-se que, ao longo do ciclo da cultura, com o aumento dos valores de Kc, tem-se também uma tendência elevatória nos valores de evapotranspiração da cultura (ETc). O mesmo raciocínio foi entendido por Silva e Klar (2002) que ao pesquisarem ETc da cultura do maracujá, verificaram que o Kc

Figura 1 - Evapotranspiração da melancia (ETc) versus coeficiente cultural (Kc)

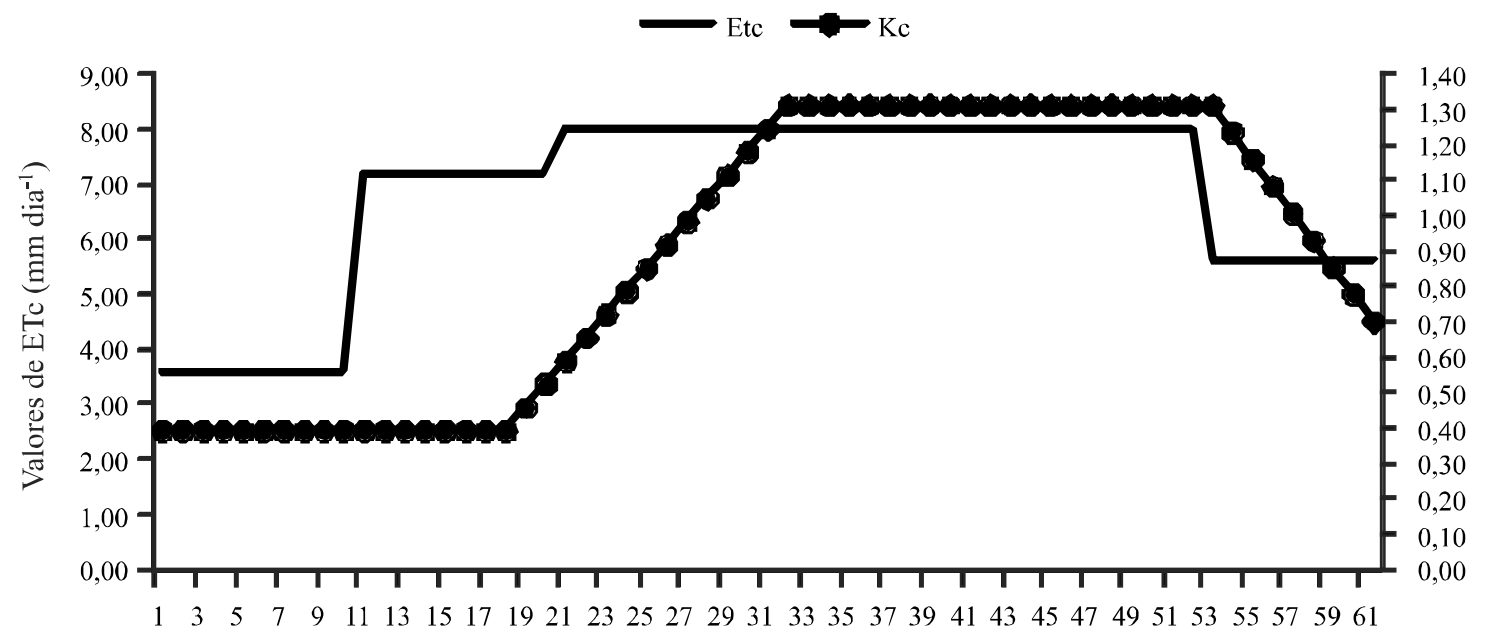

Dias do ciclo da cultura 
aumenta, conforme a cultura se desenvolve. Já Oliveira, Leião e Almeida (2010) ao pesquisarem a cultura do melão, concluíram que a ETc da cultura apresentou valores crescentes do estádio inicial até a cobertura total, caindo em seguida até a fase final da mesma.

As variáveis $\mathrm{Z}$, Kc e p deveriam ter sido fornecidas ao ISAREG, a cada estádio fenológico da cultura da melancia, mas não verificou-se na literatura, trabalhos que resultassem nestas variáveis precisas. Sendo assim, os dados de profundidade do sistema radicular, de Kc e do fator de disponibilidade de água (p) foram oriundos de reduzido número de pesquisas científicas, bem como de depoimentos de pesquisadores, nomeadamente reconhecidos, especialistas em manejo de irrigação.

O fator "p" é de grande importância na ETc, que é um fator fundamental na análise do balanço hídrico no solo, pois segundo Pereira (2004) o valor de "p" em função da ETc, não só serve para tomar em consideração os efeitos do clima mas também para responder à variação da sensibilidade das culturas em função das suas fases vegetativas. Foi notória a relação entre ETc e "p", pois nos dias em que a cultura da melancia evapotranspirou mais, ocasião em que o valor de "p" deveria ser reduzido, mas no entanto foi elevado, verificou-se déficit hídrico na cultura.

No cálculo do balanço hídrico no solo, o ISAREG foi utilizado na simulação condições para um manejo ótimo da irrigação, onde posteriormente, o calendário simulado foi comparado ao calendário de irrigação adotado pelo irrigante do PIBA.

$\mathrm{Na}$ simulação realizada pelo ISAREG para o manejo ótimo, a relação entre a evapotranspiração atual (ETa) e a evapotranspiração máxima (ETm) foi igual a 1. Portanto, o modelo simulou o balanço hídrico no solo, de forma que não houvesse excesso nem déficit de água na irrigação. A lâmina de água total requerida pela cultura da melancia, durante o ciclo de 68 dias foi de $400,9 \mathrm{~mm}$. Miranda et al. (2004) estudando o manejo da irrigação para a cultura da melancia, concluíram que a lâmina de água total requerida pela cultura, durante todo o ciclo foi de 408 mm. Todavia, Carvalho, Bezerra e Carvalho (2007) ao estudarem a melancia, em um Argissolo, verificaram que aplicando uma lâmina de $312,3 \mathrm{~mm}$ a cultura não sofreu restrição de água.

O total de água disponível no solo, ao final do ciclo da cultura foi de $32 \mathrm{~mm}$. O total acumulado de chuva, durante todo o ciclo da cultura foi de $3,2 \mathrm{~mm}$, pois durante os meses do ciclo da cultura (na simulação) a precipitação observada foi bastante reduzida (média de $1,5 \mathrm{~mm}$ ). Neste caso, a eficiência do balanço foi de $100 \%$. A água total que fica armazenada nas camadas mais profundas do solo é um fator importante, pois
Pereira (2004) afirma que baixas umidades nas camadas mais profundas do solo, representam uma reduzida condutividade hidráulica do mesmo, ou seja, significa dizer que a drenagem do solo é deficitária.

Em solos com problemas de drenagem, o que não foi o caso do solo utilizado nas simulações, recomenda-se o uso da irrigação localizada (método de irrigação utilizado pelos produtores de melancia do PIBA), pois Petillo e Castel (2007) ressaltam que a variação do conteúdo de água no solo (e conseqüentemente a variação da armazenagem de água entre estádios fenológicos) é normalmente maior sob sistema de irrigação por gotejamento, por causa da não uniformidade de distribuição da água tanto em superfície quanto em profundidade.

O modelo calculou a lâmina de água a ser aplicada, levando-se em consideração, a evapotranspiração da cultura (ETc), a precipitação, e as características físicas do solo. Nos meses de janeiro a maio, foram verificados os maiores eventos pluviométricos no Baixo Acaraú, com precipitação alcançando 12,9 mm no mês de março. No entanto, como a cultura da melancia, no processo de simulação, foi cultivada no início de setembro (precipitação média de $1,4 \mathrm{~mm}$ ), a chuva pouco colaborou para a redução na lâmina aplicada na irrigação. A lâmina bruta mínima exigida foi de 2,3 mm dia ${ }^{-1}$, no oitavo dia do ciclo da cultura. Já a lâmina bruta máxima foi de $13,9 \mathrm{~mm} \mathrm{dia}^{-1}$, na irrigação do $60^{\circ}$ dia do ciclo (Figura 2).

Foi possível observar que as lâminas aumentam a partir do $31^{\circ}$ dia do ciclo da cultura (início do mês de outubro), com um valor mínimo de 4,3 $\mathrm{mm}$ e um máximo de 13,9 mm. Isso se deve a diversos fatores, tais como: o coeficiente cultural (Kc) se eleva, a partir do estádio fenológico correspondente à idade da cultura da melancia de cerca de 28 dias, reduzindo nos últimos dias de cultivo, mas não sendo inferior ao Kc inicial; somando-se a esse fato, o maior registro de evapotranspiração de referência (ETo) foi verificado, exatamente, no mês de outubro $\left(6,34 \mathrm{~mm} \mathrm{dia}^{-1}\right)$, ou seja, com o aumento da evapotranspiração da cultura (ETc), elevou-se a necessidade da aplicação da lâmina d'água. No manejo ótimo da irrigação a lâmina aplicada total de água foi de 400,9 mm, sendo a ETc total, durante todo o ciclo da cultura de $409,1 \mathrm{~mm}$.

Portanto, verifica-se a fundamental importância de se conhecer a demanda de água da cultura da melancia, ao longo de suas fases fenológicas, visando o correto manejo da irrigação. De acordo com Fagan et al. (2006), no período inicial de desenvolvimento (germinação e emergência) a cultura requer umidade moderada no solo, enquanto as fases que requerem as maiores quantidades de 
Figura 2 - Manejo realizado pelo irrigante versus o manejo com o ISAREG

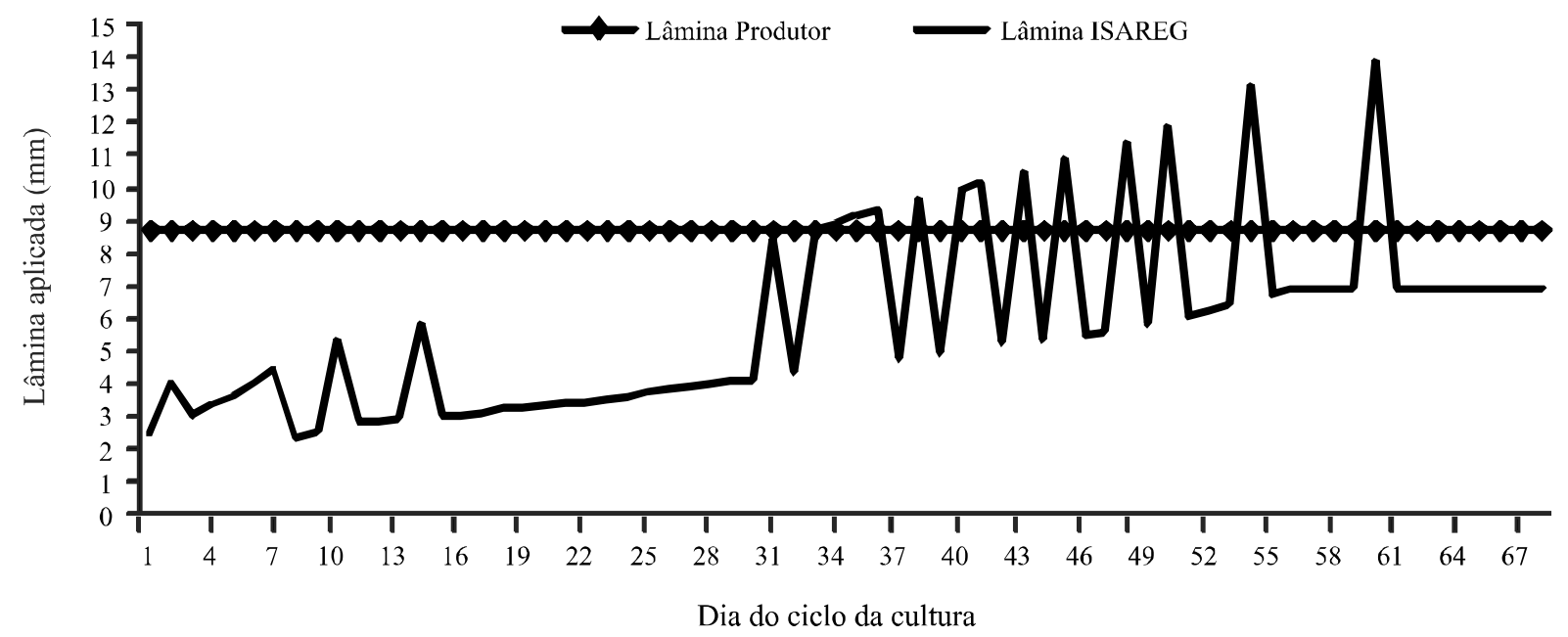

água são floração, inicio da frutificação e crescimento, e desenvolvimento das ramas laterais. Contudo, ainda existe carência de informação para que o manejo da irrigação seja efetuado de maneira racional.

Analisando a demanda hídrica calculada pelo ISAREG, nos dias de máxima demanda $(13,9 \mathrm{~mm})$ o irrigante deveria funcionar o sistema de irrigação durante 4,8 horas por dia, mas nos dias de demanda mínima $(2,3 \mathrm{~mm})$, o sistema funcionaria 0,8 horas (47,5 minutos). No entanto, viabilizando a prática de aplicação, numa média, com a demanda de $5,9 \mathrm{~mm}$, o irrigante deveria acionar o sistema por 2 horas diárias.

Os irrigantes do PIBA irrigam a cultura da melancia por 3 horas diárias. Em média, aplicam uma lâmina de $8,7 \mathrm{~mm}$ por dia, em seus cultivos de melancia. Levando-se em consideração que a duração média do ciclo da melancia é de 68 dias, então durante todo o ciclo da cultura os irrigantes estão aplicando, aproximadamente, 591,6 $\mathrm{mm}$.

No manejo ótimo da irrigação, realizado pelo ISAREG, a lâmina aplicada total de água foi de 400,9 mm. Esta diferença entre lâminas de $190,7 \mathrm{~mm}$ pode ser em decorrência da indicação de manejo da cultura da melancia, realizada pelo DNOCS (Departamento Nacional de Obras Contra as Secas), através do projeto executivo, quando do planejamento de implantação do perímetro irrigado Baixo Acaraú, pois o supracitado órgão costumava utilizar métodos de determinação da evapotranspiração não indicados pela FAO (Food Agriculture Organization).

A Figura 2 mostra a comparação entre o manejo da irrigação realizado pelo irrigante do Baixo Acaraú e o manejo ótimo de irrigação, calculado pelo ISAREG.
Foi possível observar que até o $30^{\circ}$ dia do ciclo da cultura da melancia, o irrigante está aplicando mais água do que a cultura necessita. Esta diferença é mínima em 2,9 mm e máxima em 6,4 mm. Para o mesmo período do ciclo da melancia, Miranda et al. (2004) aplicaram uma lâmina de $2,61 \mathrm{~mm}$. Já a partir do $31^{\circ}$ dia do ciclo até o $60^{\circ}$ dia, o irrigante está aplicando menos água do que a planta necessita. Neste dia uma lâmina de 5,2 mm é aplicada a menos, ou seja, ocorre um déficit hídrico de $52 \mathrm{~m}^{3} \mathrm{ha}^{-1}$ nas culturas de melancia cultivadas no Baixo Acaraú. Nos últimos 8 (oito) dias do ciclo da cultura, volta a ocorrer uma superestimativa, e o irrigante volta a aplicar mais água do que o demandado pela cultura da melancia. Os irrigantes dos perímetros continuam a aplicar água às culturas de forma errônea, tornandose necessário gerar, adaptar e difundir tecnologias de manejo adequado de irrigação.

Considerando o plantio no mês de setembro, o irrigante do Baixo Acaraú está aplicando em excesso cerca de 215,2 $\mathrm{mm}$ de água à cultura da melancia. Também, o mesmo está proporcionando um déficit hídrico de 24,2 mm, durante todo o ciclo da cultura. $\mathrm{O}$ estresse sofrido pela cultura traduz-se pela diminuição da taxa de evapotranspiração e, conseqüentemente, das funções fisiológicas que com ela se relacionam; como a respiração, a fotossíntese e a assimilação (PEREIRA, 2004). Provavelmente, a água aplicada a mais, deva estar, em quase sua totalidade sendo percolada, devido às características físicas do solo do Baixo Acaraú, traduzindo em custos para os irrigantes. Já o déficit se dá devido à maior evapotranspiração da cultura nos estádios de máxima cobertura, de floração e de frutificação. 


\section{CONCLUSÃO}

No processo de aplicação do ISAREG, as necessidades hídricas da melancia foram simuladas. A evapotranspiração da cultura variou de 3,59 a 8,01 $\mathrm{mm} \mathrm{dia}^{-1}$, ao longo do ciclo da melancia. Foi elaborado um calendário de irrigação, para a cultura da melancia, onde as lâminas a serem aplicadas diariamente variaram de $2,4 \mathrm{~mm}$, nos primeiros dias do ciclo da melancia a $13,9 \mathrm{~mm}$, nas fases de maiores demandas hídricas da cultura. A pesquisa evidenciou que os irrigantes do Perímetro Irrigado Baixo Acaraú, no cultivo da melancia estão manejando mal os recursos hídricos. Durante todo o ciclo da cultura, o irrigante está aplicando em excesso cerca de 215,2 mm de água, e também está proporcionando um déficit hídrico de $24,2 \mathrm{~mm}$ à cultura.

\section{AGRADECIMENTOS}

A Universidade Federal do Ceará, pelos conhecimentos adquiridos. Ao $\mathrm{CNPq}$, pelo apoio financeiro (bolsa de estudos) à pesquisa.

\section{REFERÊNCIAS}

ANDRADE JÚNIOR, A. S. et al. Produção e qualidade de frutos de melancia à aplicação de nitrogênio via fertirrigação. Revista Brasileira de Engenharia Agrícola e Ambiental, v. 10, n. 04, p. 836-841, 2006.

ALLEN, R. G. et al. An update for the calculation of reference evapotranspiration. ICID Bulletin, v. 43, n. 02, p. 35-92, 1994.

ANNAN, C. Relatório anual da Organização das Nações Unidas - ONU. Roma, Itália. 2005. 256 p.

AQUINO. D. N. et al. Impacto do manejo da irrigação sobre os recursos solo e água. Revista Ciência Agronômica, v. 39, n. 02, p. 225-232, 2008.

BEZERRA, F. M. L.; OLIVEIRA, C. H. C. Evapotranspiração máxima e coeficiente de cultura nos estádios fenológicos da melancia irrigada. Revista Brasileira de Engenharia Agrícola e Ambiental, v. 03, n. 02, p. 173-177, 1999.

CARVALHO, L. C. C.; BEZERRA, F. M. L; CARVALHO, M. A. R. Evapotranspiração e coeficientes de cultivo da melancia sem sementes. Revista Ciência Agronômica, v. 39, n. 01, p. 53-59, 2007.

FAGAN,E. B. et al. Consumo hídrico do meloeiro hidropônico em ambiente protegido. Revista Brasileira de Agrometeorologia, v. 14, n. 03, p. 318-326, 2006.
FIGUEIRÊDO, V. B. et al. Evapotranspiração da cultura da melancia irrigada com água de diferentes salinidades. Revista Engenharia Agrícola, v. 29, n. 02, p. 231-240, 2009.

KASHYAP, P. S.; PANDA, R. K. Evaluation of evapotranspiration estimation methods and development of crop-coefficients for potato crop in a sub-humid region. Agricultural Water Management, v. 34, n. 50. p. 09-25, 2001.

LÓPEZ-URREA, R. et al. Testing evapotranspiration equations using lysimeter observations in a semiarid climate. Agricultural Water Management, v. 08, n. 05, p.15-26, 2006.

MIRANDA, F. R. et al. Evapotranspiração máxima e coeficientes de cultivo para a cultura da melancia irrigada por gotejamento. Revista Ciência Agronômica, v. 35, n. 01, p. 36-43, 2004.

MOREIRA, L. C. J. Evapotranspiração da melancia irrigada por meio Sebal, Balanço Hídrico e Correlações Turbulentas. 2009. 93 f. Dissertação (Mestrado em Irrigação e Drenagem) Universidade Federal do Ceará, Fortaleza, 2009.

MOREIRA, L. C. J. et al. Variabilidade local e regional da evapotranspiração estimada pelo algoritmo SEBAL. Revista Engenharia Agrícola, Jaboticabal, v. 30, n. 06, p. 11481159, 2010.

OLIVEIRA, J. J. G. Evapotranspiração máxima e coeficientes de cultivo da melancia (Citrullus lanatus, Schrad) através de lisímetro de pesagem de precisão para a região litorânea do Ceará. 1999. 121 f. Dissertação (Mestrado em Irrigação e Drenagem) - Universidade Federal do Ceará, Fortaleza, 1999.

OLIVEIRA, G. M.; LEITÃO, M. M. V. B. R; ALMEIDA, A. C. Determinação da evapotranspiração e dos coeficientes de cultura para as diferentes fases de desenvolvimento do melão (Cucumis melo L.) na região norte da Bahia. Revista Verde, v. 05, n. 02, p. 142-151, 2010.

PEREIRA, L. S. Necessidades de Água e Métodos de Rega. Lisboa: Publ. Europa-América, 2004. 313 p.

PETILLO, M. G.; CASTEL, J. R. Water balance and crop coefficient estimation of a citrus orchand in Uruguay. Spanish Journal of Agricultural research, v. 03, n. 05, p. 232-243, 2007.

SANTANA, E. W. et al. Pacto das Águas - "Iniciando o Diálogo". Fortaleza: Assembléia Legislativa do Estado do Ceará. 2008. 63 p.

SISTEMA DE INFORMAÇÕES DOS RECURSOS HÍDRICOS DO CEARÁ. Dados hidroagrícolas do Baixo Acaraú. Fortaleza, CE, 2002 Disponível em:<http//www.atlas.srh.ce.gov. br>. Acesso em: 15 fev. 2010.

SILVA, A. A. G.; KLAR, A. E. Demanda hídrica do maracujazeiro Amarelo (Passiflora edulis sims f. flavicarpa deg.). Revista Irriga, v. 07, n. 03, p. 185-190, 2002. 